\title{
POTENTIAL MECHANISM OF LEFT VENTRICULAR OUTFLOW TRACT OBSTRUCTION AFTER MITRAL RING ANNULOPLASTY
}

Paul Dagum, MD, $\mathrm{PhD}^{\mathrm{a}}$

G. Randall Green, $\mathrm{MD}^{\mathrm{a}}$

Julie R. Glasson, MDa

George T. Daughters, MS ${ }^{a, b}$

Ann F. Bolger, $\mathrm{MD}^{\mathrm{c}, \mathrm{d}}$

Linda E. Foppiano, MD

Neil B. Ingels, Jr, $\mathrm{PhD}^{\mathrm{a}, \mathrm{b}}$

D. Craig Miller, MD ${ }^{a, f}$
Objectives: The purpose of this study was to explore whether geometric changes that predispose to left ventricular outflow tract obstruction after mitral ring annuloplasty are coupled to subvalvular apparatus disturbances. Methods: Radiopaque markers were implanted in sheep: 9 in the ventricle, 1 in the high interventricular septum, 1 on each papillary muscle tip, 8 around the mitral anulus, 4 on the anterior mitral leaflet, and 2 on the posterior leaflet. One group served as control $(n=5)$; the others were randomized to undergo annuloplasty with the Duran ring (n = 6; Medtronic, Inc, Minneapolis, Minn) or Carpentier-Edwards Physio ring ( $n=6$; Baxter Healthcare Corp, Irvine, Calif). After a 7- to 10-day recovery period, 3-dimensional marker coordinates were measured with biplane videofluoroscopy. Results: At the beginning of ejection, (1) the anterior leaflet was displaced toward the left ventricular outflow tract; (2) the normal atrially flexed anterior anulus was flattened into the left ventricular outflow tract; (3) the posterior anulus was displaced toward the left ventricular outflow tract; (4) the anterior papillary muscle was displaced septally; and (5) the posterior papillary muscle was dislocated inwardly toward the anterior papillary muscle in the Physio ring group compared with the control group. During ejection, all these structures moved septally, encroaching further on the left ventricular outflow tract. In the Duran ring group, only the posterior anulus was displaced toward the left ventricular outflow tract; the anterior leaflet was not displaced toward the left ventricular outflow tract, and it did not move septally during ejection. Conclusions: The semirigid Physio ring was associated with perturbations in annular dynamics that caused changes in papillary muscle geometry. We propose an integrated valvular-subvalvular mechanism to explain displacement of the anterior leaflet into the left ventricular outflow tract after mitral ring annuloplasty. (J Thorac Cardiovasc Surg 1999;117:472-80)
L eft ventricular outflow tract (LVOT) obstruction after mitral valve ring annuloplasty was first described by Termini and colleagues ${ }^{1}$ in 1977 . Since that first case, LVOT obstruction has been reported to complicate $2 \%$ to $10 \%$ of ring annuloplasties. ${ }^{2-8}$ Almost all

From the Department of Cardiovascular and Thoracic Surgery, ${ }^{a}$ the Division of Cardiovascular Medicine, ${ }^{c}$ and the Department of Anesthesia, e Stanford University School of Medicine, Stanford, Calif; Cardiac Surgery ${ }^{\mathrm{f}}$ and Cardiology Sections, ${ }^{\mathrm{d}}$ Department of Veterans Affairs Medical Center, Palo Alto, Calif; and the Department of Cardiovascular Physiology and Biophysics, ${ }^{\text {b }}$ Research Institute of the Palo Alto Medical Foundation, Palo Alto, Calif.

Read at the Twenty-fourth Annual Meeting of The Western Thoracic Surgical Association, Whistler, British Columbia, June 24-27, 1998.

Supported in part by grants HL-29589 and HL-48837 from the National Heart, Lung, and Blood Institute. P.D and G.R.G. were of these complications arise in patients who have type II (or excessive) mitral leaflet motion as the result of either myxomatous disease or fibroelastic deficiency and patients who have undergone complete ring annuloplasty, rather than other types of annular remodeling.

supported by NHLBI Individual Research Service Awards HL10000-01 and HL-09569, respectively.

Received for publication July 15, 1998; revisions requested Sept 18, 1998; revisions received Nov 24, 1998; accepted for publication Nov 24, 1998.

Address for reprints: D. Craig Miller, MD, Department of Cardiovascular and Thoracic Surgery, Falk Cardiovascular Research Center, Stanford University School of Medicine, Stanford, CA 94305-5247.

$12 / 6 / 96201$ 
The mechanism of LVOT obstruction is displacement of the anterior mitral valve leaflet (AMVL) into the LVOT during systolic ejection; the actual cause of this displacement, however, remains debated. Several theories $^{5-8}$ have been proposed, but none completely explains LVOT obstruction. A complete theory must consider the integrated effects of ring annuloplasty on the subvalvular complex and on the anulus and how these perturbations predispose to LVOT obstruction.

Recent research on LVOT obstruction in hypertrophic cardiomyopathy (HCM) has indicated that septal papillary muscle dislocation may be the primary mechanism. ${ }^{9-12}$ We therefore determined whether, through a similar mechanism, geometric changes in the anulus that predispose to LVOT obstruction after ring annuloplasty are coupled with disturbances in the subvalvular apparatus. Moreover, because both rigid and flexible annuloplasty rings have been shown to abolish changes in annular area and perimeter, ${ }^{13}$ we explored whether either ring type leads preferentially to geometric annular changes that might predispose to LVOT obstruction.

\section{Methods}

Seventeen adult castrated male sheep $(67 \pm 8 \mathrm{~kg}$ [mean \pm $\mathrm{SD}]$ ) were assigned to 3 groups, all of which underwent placement of myocardial markers. Five animals served as controls; the remainder underwent mitral ring annuloplasty with a flexible Duran ring ( $\mathrm{n}=6$; Medtronic, Inc, Minneapolis, Minn) or a semirigid Carpentier-Edwards Physio ring $(n=6$; Baxter Healthcare Corp, Irvine, Calif). Postoperative care and data collection were identical for all groups.

Surgical preparation. The animal was intubated and placed on mechanical ventilation (Servo Anesthesia Ventilator, Siemens-Elema AB, Division of Elema-Schönander, Inc, Solna, Sweden); general anesthesia was maintained with inhalational isofluorane (1\%-2.2\%). A left thoracotomy was performed through the fifth intercostal space, and pneumatic occluders (In Vivo Metric Systems, Healdsburg, Calif) were placed around the superior and inferior venae cavae. The heart was suspended in a pericardial cradle, and 9 miniature radiopaque tantalum markers (internal diameter, $0.8 \mathrm{~mm}$; outer diameter, $1.3 \mathrm{~mm}$; length, 1.5-3.0 $\mathrm{mm}$ ) were inserted into the left ventricular (LV) epicardium and septum as described previously. ${ }^{14}$ An additional LV endocardial marker was placed in the septum of the LVOT with the use of epicardial echocardiographic guidance, which was also used (with color Doppler flow mapping) to assess competence and anatomy of the mitral valve. The myocardial marker array analyzed in this experiment is shown in Fig 1, A. The animal was placed on cardiopulmonary bypass cannulating the left carotid artery and right atrium. Working through a left atriotomy, we sutured 8 tantalum radiopaque markers approximately 45 degrees from one another around the circumference of the mitral anulus. Four markers were sutured to the AMVL along its central meridian, and 2 markers were sutured to the central scallop of the posterior leaflet, also along the central meridian. We sized the rings (Duran ring, 29 $\mathrm{mm}[\mathrm{n}=1]$ and $31 \mathrm{~mm}[\mathrm{n}=5]$; Physio ring, $28 \mathrm{~mm}[\mathrm{n}=6])$ using both the distance between the fibrous trigones and the area of the anterior leaflet; the rings were secured with 10 to 12 interrupted horizontal mattress sutures. A micromanometer pressure transducer (PA4.5-X6; Konigsberg Instruments, Inc, Pasadena, Calif) was placed in the LV chamber through the apex. The leads from the micromanometer and the tubing from the superior and inferior venae cavae pneumatic occluders were exteriorized through the skin between the scapulae. The incisions were closed, and the animal recovered in the experimental animal cardiac surgical intensive care unit.

Experimental design. After a recovery period ( $8 \pm 1$ days [mean $\pm \mathrm{SD}]$ ), each animal was taken to the experimental animal cardiac catheterization laboratory for study. The animals were premedicated with ketamine, intubated, and mechanically ventilated (veterinary anesthesia ventilator 2000; Hallowell EMC, Pittsfield, Mass) with $100 \%$ oxygen. Transthoracic echocardiography with color Doppler sonography was used to assess proper seating of the ring and competence of the valve. Simultaneous biplane videofluoroscopic and hemodynamic data were acquired with the animal in the right lateral decubitus position. Animals were studied in normal sinus rhythm after autonomic blockade and with ventilation arrested at end-expiration during data acquisition runs to minimize the effects of respiratory variation. All animals received humane care in compliance with the "Principles of Laboratory Animal Care" formulated by the National Society for Medical Research and the "Guide for Care and Use of Laboratory Animals" prepared by the National Academy of Sciences and published by the National Institutes of Health (DHEW [NIH] Publication 23 to 85, revised 1985). This study was approved by the Stanford Medical Center Laboratory Research Animal Review Committee and conducted according to Stanford University policy.

Data acquisition. A Philips Optimus 2000 biplane Lateral ARC 2/poly DIAGNOST C2 system (Philips Medical Systems, North America Company) was used to record videofluoroscopic data at $60 \mathrm{~Hz}$ with the image intensifiers in the 9-inch mode. Two-dimensional images from each of the 2 radiograph views (45-degree right anterior oblique and 45degree left anterior oblique) were digitized and merged to yield 3-dimensional coordinates for each radiopaque marker every $16.7 \mathrm{~ms}$. The details of this data acquisition process have been reported previously. ${ }^{15}$ Analog LV pressure and electrocardiograph voltage were recorded on the video images during data acquisition and were digitized simultaneously with marker coordinates.

Data analysis. End-systole was defined as the videofluoroscopic frame preceding the maximum negative rate of pressure $\left(-\mathrm{dP}_{\mathrm{dt}} \mathrm{max}_{\max }\right)$; end-diastole was defined as the videofluoroscopic frame containing the peak of the electrocardiograph $\mathrm{R}$ wave.

$L V$ volume. We calculated an instantaneous estimate of $L V$ volume every $16.7 \mathrm{~ms}$ from the epicardial LV marker silhouette using a multiple tetrahedral model and corrected for LV 


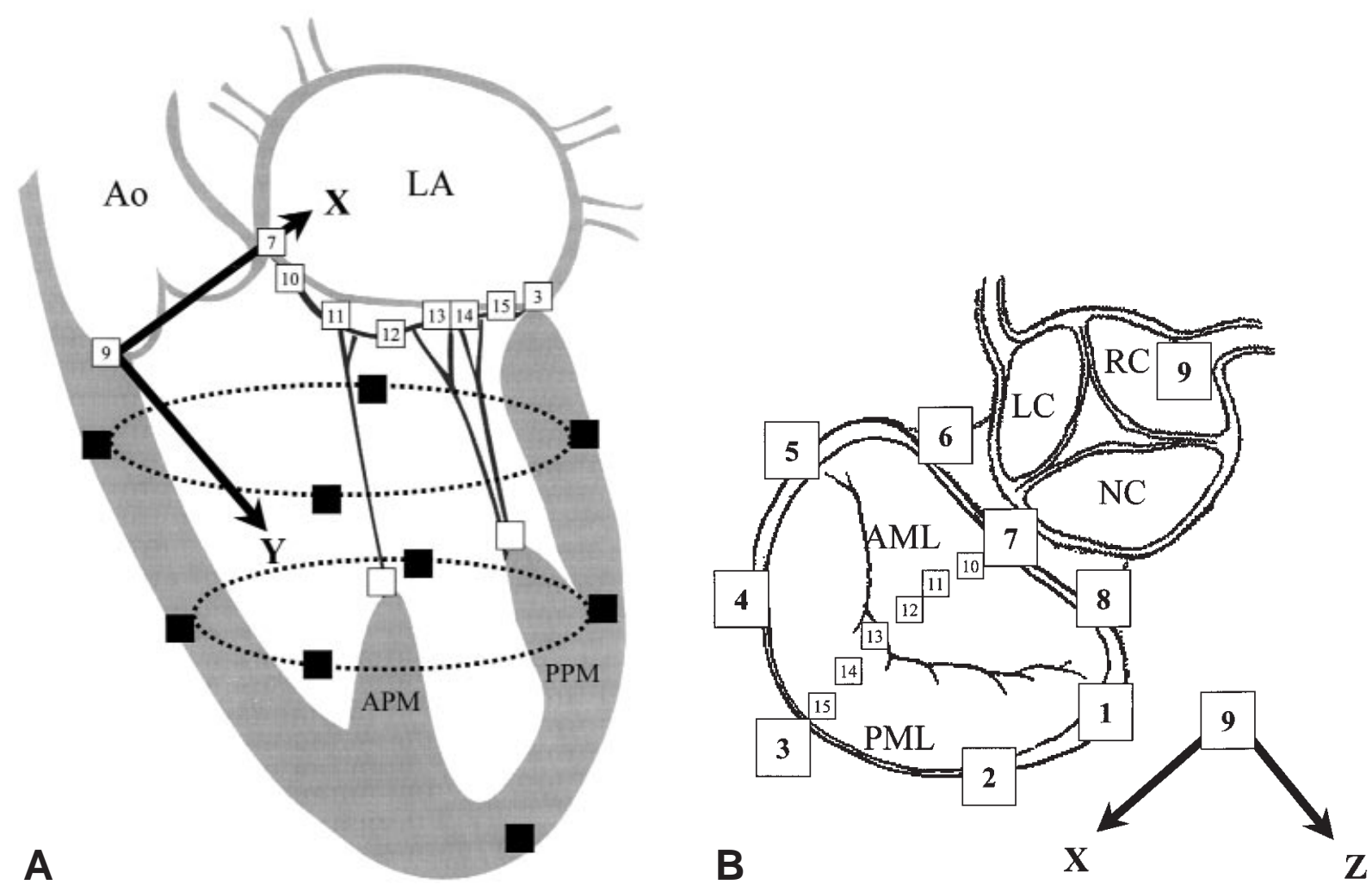

Fig 1. A, The myocardial-marker array analyzed in this experiment consisted of 9 subepicardial markers (solid squares) and 17 additional markers positioned as follows: 8 markers equidistantly around the mitral anulus (not shown), 4 markers equidistantly along the central meridian of the AMVL (markers 10-13), 2 markers along the central meridian of the central cusp of the posterior leaflet (markers 14 and 15), 1 marker on each papillary muscle tip (open squares), and 1 marker in the high-septal LVOT (marker 9). The coordinate system that we used to compute distances, displacements, and angles had its origin at the high-septal marker (marker 9). The Y axis was directed through the LV apex marker; the $\mathrm{X}$ axis was orthogonal to the $\mathrm{Y}$ axis and in the direction of the saddle-horn marker (marker 7); and the $\mathrm{Z}$ axis was orthogonal to the $\mathrm{X}$ and $\mathrm{Y}$ axes and in the direction of the posterior commissure. Ao, Aorta; $L A$, left atrium; APM, anterolateral papillary muscle; $P P M$, posteromedial papillary muscle. B, View of the aortomitral fibrous skeleton displaying annular mitral leaflet $(A M L)$, LVOT markers, and coordinate system used for analysis. $R C$, Right coronary; $L C$, left coronary; $N C$, noncoronary; $P M L$, posterior mitral leaflet.

convexity. Although epicardial LV volume calculated in this manner overestimates true chamber LV volume, the change in epicardial LV volume is an accurate measurement of the relative change in chamber $\mathrm{LV}$ volume. ${ }^{16}$ Thus stroke volume can be accurately calculated from the change in epicardial LV volume, but ejection fraction, or stroke volume normalized to epicardial LV volume, is substantially underestimated.

LV systolic function. End-systolic elastance, calculated from the end-systolic pressure-volume relationship, and preload recruitable stroke work, calculated from stroke work and end-diastolic volume, were used to assess global LV systolic function.

Coordinate system. External, fixed laboratory coordinates were transformed to a floating coordinate system fixed to the heart, with the origin at the high-septal LVOT marker (marker 9; Fig 1, A). The Y axis was directed through the LV apex; the $\mathrm{X}$ axis was directed orthogonal to the $\mathrm{Y}$ axis (approximately in the direction of the anterior annular saddlehorn [marker 7, located midway between the fibrous trigone markers]; Fig 1, B); and the $\mathrm{Z}$ axis was directed orthogonal to both the $\mathrm{X}$ and $\mathrm{Y}$ axes. Septal-directed motion is displacement along the $\mathrm{X}$ axis toward the high septal marker; apical displacement is displacement along the $\mathrm{Y}$ axis away from the origin and toward the apical marker; and commissure displacement is displacement along the $\mathrm{Z}$ axis. All distances, angles, and displacements were calculated relative to this internal, moving coordinate system. Because the coordinate system is fixed to the heart, changes in these measurements during the cardiac cycle are not corrupted by rigid body rotation and translation artifacts.

The mitral valvular-subvalvular complex. The aortomitral angle was defined as the angle subtended at the saddlehorn 


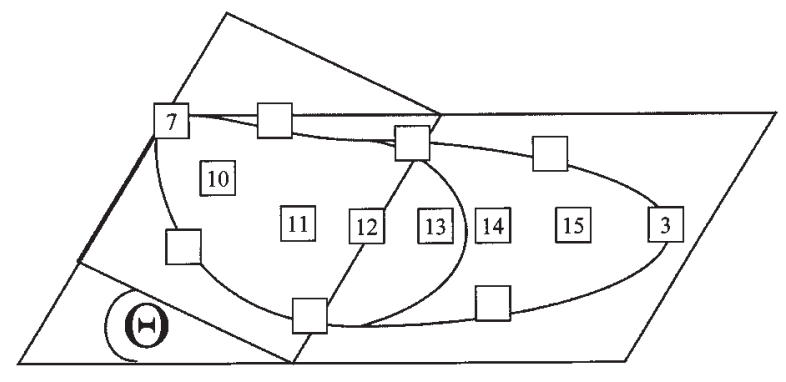

Fig 2. Mitral annular flexion angle, $\theta$, is calculated by the angle subtended by 2 least-squares planes fitted to the anterior and commissure annular markers and to the posterior and commissure annular markers. These planes intersect approximately along a line through the commissures.

Table I. Hemodynamic parameters in each of the 3 groups

\begin{tabular}{lccc}
\hline & Control & Duran ring & Physio ring \\
\hline $\mathrm{HR}\left(\mathrm{min}^{-1}\right)$ & $93 \pm 8$ & $102 \pm 6$ & $98 \pm 10$ \\
$\mathrm{ESP}(\mathrm{mm} \mathrm{Hg})$ & $108 \pm 11$ & $87 \pm 12^{*}$ & $91 \pm 14$ \\
$\mathrm{EDV}(\mathrm{mL})$ & $170 \pm 54$ & $183 \pm 43$ & $156 \pm 23$ \\
$\mathrm{ESV}(\mathrm{mL})$ & $143 \pm 46$ & $151 \pm 30$ & $127 \pm 17$ \\
$\mathrm{SV}(\mathrm{mL})$ & $27 \pm 9$ & $32 \pm 16$ & $29 \pm 8$ \\
$\mathrm{EF}$ & $0.16 \pm 0.03$ & $0.17 \pm 0.05$ & $0.18 \pm 0.03$ \\
$\mathrm{dP} / \mathrm{dt}_{\max }$ & $1490 \pm 211$ & $1265 \pm 295$ & $1356 \pm 269$ \\
$\quad$ & & & \\
\hline
\end{tabular}

$H R$, Heart rate; $E S P, \mathrm{LV}$ end-systolic pressure; $E D V, \mathrm{LV}$ end-diastolic volume; $E S V, \mathrm{LV}$ end-systolic volume; $S V, \mathrm{LV}$ stroke volume; $E F, \mathrm{LV}$ ejection fraction. Data are expressed as mean \pm SD.

*The difference is significant at $P<.05$ between Duran ring and control groups by analysis of variance with post hoc Bonferroni correction.

marker by the high-septal marker and the lateral annular marker (markers 7 and 3, respectively; Fig 1, B). Markers 2, 3 , and 4 defined the posterior anulus; markers 6,7 , and 8 defined the anterior (fibrous) anulus, and markers 1 and 5 defined the commissures (Fig 1, B). Markers 7 and 10 through 13 defined the central meridian of the AMVL; and markers 3, 14, and 15 defined the central meridian of the middle scallop of the posterior mitral valve leaflet (PMVL). The flexion angle between the anterior and the posterior mitral anulus was calculated from the angle subtended by 2 leastsquares planes fitted to the anterior and commissure annular markers and to the posterior and commissure annular markers (Fig 2). Displacements in the X, Y, and Z directions of the anterior anulus, posterior anulus, AMVL, and PMVL were calculated from the sample mean of the displacements of all the markers that defined these structures.

Statistical analysis. All data are reported as mean \pm 1 SD. For each animal, data represent the mean of 3 consecutive cardiac cycles. We compared data between groups using analysis of variance with post hoc Bonferroni corrections. We compared the data within each group (control, Duran

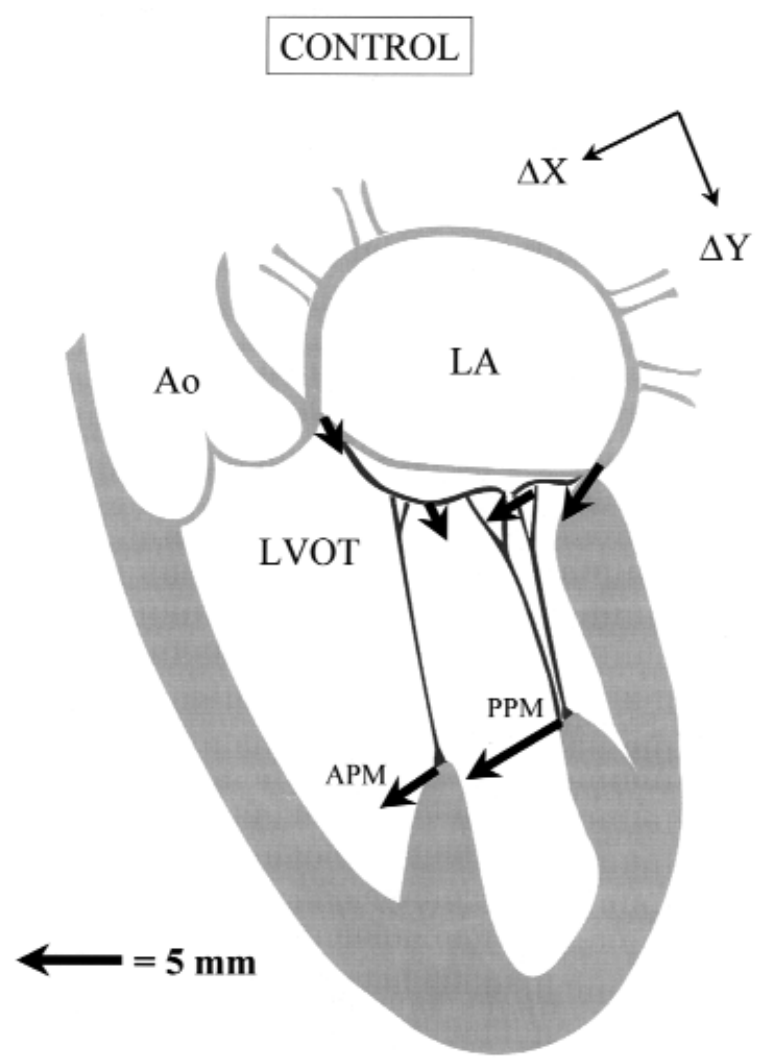

Fig 3. Septal-apical $(X, Y)$ 2-dimensional view of the LVOT and mitral-valve complex in the control group. Arrows show the significant septal-apical movement that occurred during systolic ejection. The origin of the coordinate system is at the high-septal LVOT marker (not shown). Displacement in the Y direction is toward the LV apex; displacement in the $\mathrm{X}$ direction is toward the LV septum. Ao, Aorta; $L A$, left atrium; $L V O T$, left ventricular outflow tract; $A P M$, anterolateral papillary muscle; $P P M$, posteromedial papillary muscle.

ring, and Physio ring) using the Student $t$ test for paired observations.

\section{Results}

Sheep weights were not significantly different among the groups (control, $62 \pm 9 \mathrm{~kg}$; Duran ring, $69 \pm 8 \mathrm{~kg}$; and Physio ring, $70 \pm 8 \mathrm{~kg}$ ). Necropsy confirmed that all annuloplasty rings were seated properly. Transthoracic color Doppler echocardiography revealed that neither mitral regurgitation nor perivalvular leaks were observed in any animal at the time of data acquisition.

Hemodynamics. Heart rate, end-systolic volume, end-diastolic volume, and stroke volume were not different between the 3 groups (Table I). End-systolic pressure was lower in the Duran ring group than in the control or Physio ring groups. Load-dependent (ejec- 


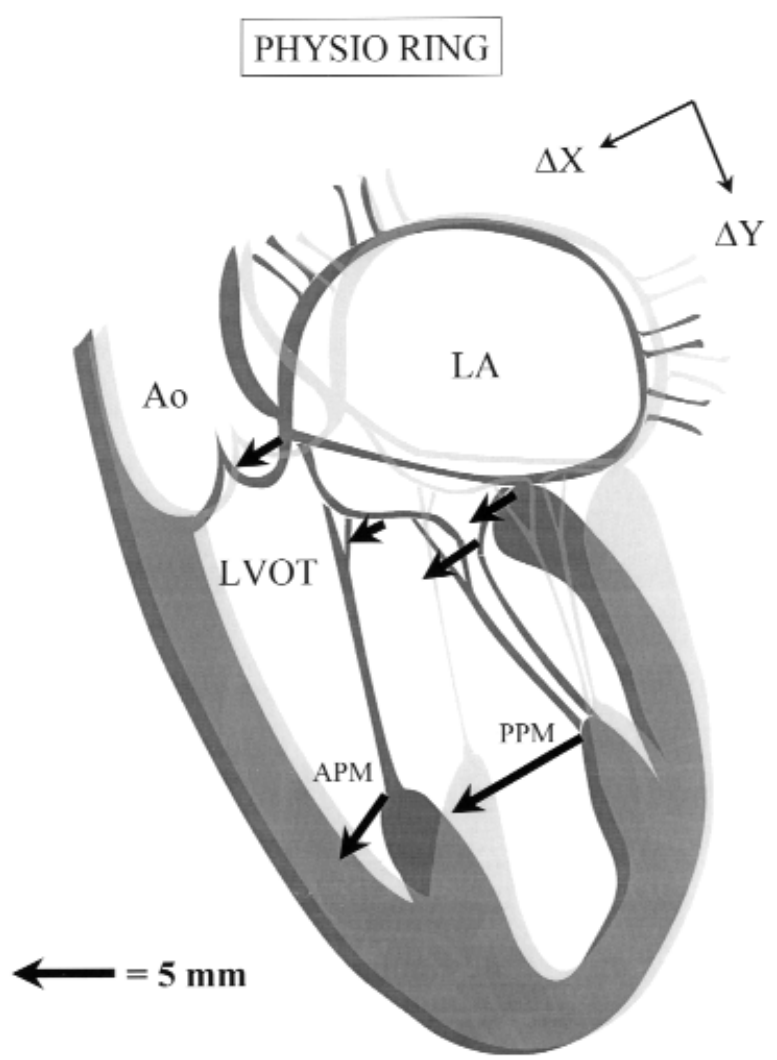

Fig 4. Septal-apical $(X, Y)$ 2-dimensional view of the LVOT and mitral-valve complex in the Physio ring group superimposed on the same 2-dimensional view of the control group (in light gray) at end IVC. Arrows show the significant septal-apical movement that occurred in the Physio ring group relative to the control group during systolic ejection. Ao, Aorta; $L A$, left atrium; $A P M$, anterolateral papillary muscle; $P P M$, posteromedial papillary muscle.

tion fraction, peak maximum rate of rise of $\mathrm{LV}$ pressure $\left[\mathrm{LV},+\mathrm{dP} / \mathrm{dt}_{\max }\right]$; Table I) and load-independent (endsystolic elastance; preload recruitable stroke work) indices of systolic function were not statistically different in the 3 groups.

For the results that follow, we present only statistically significant displacements with respect to the control group at the beginning of ejection and statistically significant motion during ejection of mitral valve structures. Insignificant displacements and movements are referred to as "fixed" or "unchanged."

Control group during ejection. A summary of the significant septal and apical changes in the mitral valve complex during ejection in the control group is presented in Fig 3 . The posterior anulus moved $2.1 \pm 0.5$ mm septally $(P<.001), 1.0 \pm 1.2 \mathrm{~mm}$ apically $(P=$ .020 ), and $1.2 \pm 0.9 \mathrm{~mm}$ toward the anterior commis-

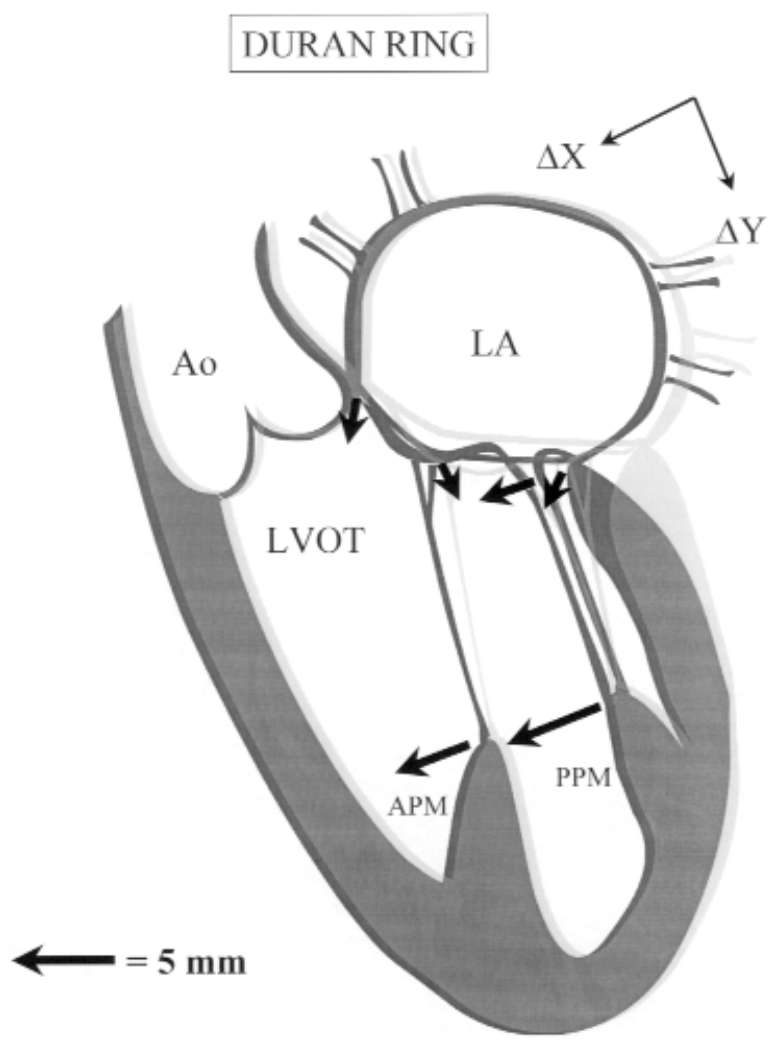

Fig 5. Septal-apical $(X, Y)$ 2-dimensional view of the LVOT and mitral valve complex in the Duran ring group superimposed on the same 2-dimensional view of the control group (in light gray) at end IVC. Arrows show the significant septal-apical movement that occurred in the Duran ring group relative to the control group during systolic ejection. Ao, Aorta; $L A$, left atrium; $A P M$, anterolateral papillary muscle; $P P M$, posteromedial papillary muscle.

sure $(P<.001)$. The anterior anulus moved $0.8 \pm 0.7$ $\mathrm{mm}$ apically $(P=.006)$ and did not change in the other 2 directions. To accommodate the anteroseptal motion of the posterior anulus without perturbing the anterior anulus, the anterior mitral anulus flexed away from the LVOT during systole. The anterior mitral anulus in the control group flexed $7 \pm 5$ degrees during systole $(P=$ .04 ), from a flexion angle of $15 \pm 8$ degrees at the beginning of ejection to a flexion angle of $22 \pm 7$ degrees at the end of systole.

The posterior leaflet moved $1.8 \pm 0.6 \mathrm{~mm}$ septally $(P$ $<.001)$ and $0.8 \pm 0.7 \mathrm{~mm}$ toward the anterior commissure $(P=.002)$, paralleling the motion of the posterior anulus during that period. In contrast, the anterior leaflet moved slightly $(0.7 \pm 0.6 \mathrm{~mm})$ apically $(P<$ $.001)$ but did not move in the other directions. Both papillary muscles moved septally (anterolateral papil- 
lary, $2.3 \pm 0.8 \mathrm{~mm} ; P=.018$; posteromedial papillary $5.2 \pm 0.8 \mathrm{~mm} ; P<.001)$ but did not change significantly in the other directions.

Geometric changes at the beginning of ejection in both ring groups. The annuloplasty rings were associated with different changes in the geometric configuration of the mitral valve complex at the beginning of ejection (end IVC). In the Physio ring group, the geometric changes in the anulus, leaflets, and papillary muscles were all directed toward the septum with respect to the control group at end IVC. The posterior anulus was displaced $6.9 \pm 3.5 \mathrm{~mm}$ septally $(P=.001)$ toward the LVOT with respect to the control group at end IVC. The anterior anulus was displaced $3.9 \pm 5.8$ mm septally $(P=.035)$. There was no displacement of the anulus in either the apical or commissure direction, and the baseline flexed configuration of the mitral anulus was abolished by the Physio ring. Both leaflets were also displaced toward the LVOT (anterior leaflet, $3.2 \pm$ $5.4 \mathrm{~mm}[P=.034]$; posterior leaflet $4.8 \pm 2.7 \mathrm{~mm}[P<$ $.001])$, and the anteromedial papillary muscle was displaced $3.1 \pm 1.6 \mathrm{~mm}$ septally $(P=.033)$.

In the Duran ring group, the posterior anulus was displaced $4.1 \pm 4.7 \mathrm{~mm}$ septally $(P=.018)$ and $4.4 \pm 5.4$ mm toward the posterior commissure $(P=.018)$ with respect to the control group at end IVC. The anterior anulus position remained unchanged compared with the control group, and the anulus partially maintained its flexed configuration of $11 \pm 7$ degrees throughout ejection. The anterior and posterior leaflets, as a group, were displaced $2.8 \pm 6.4 \mathrm{~mm}$ toward the atrium $(P=$ .034) but were not displaced toward the LVOT. Both papillary muscles were unchanged from their positions in the control group at end IVC.

Ring groups during ejection. The significant septal and apical changes in the mitral valve complex during ejection in the Physio ring group are shown in Fig 4. During ejection, the posterior anulus moved $1.9 \pm 1.2$ mm septally $(P<.001)$, and the anterior anulus moved $1.3 \pm 1.0 \mathrm{~mm}$ farther into the LVOT $(P<.001)$. The anulus did not move in the apical or commissure directions. Both leaflets moved toward the LVOT (anterior leaflet, $0.7 \pm 1.3 \mathrm{~mm}[P=.024]$; posterior leaflet, $2.0 \pm$ $1.3 \mathrm{~mm}[P=.001])$. The anterolateral papillary muscle moved $3.1 \pm 1.3 \mathrm{~mm}$ septally $(P=.010)$ and $1.1 \pm 0.6$ $\mathrm{mm}$ atrially $(P=.030)$. The posteromedial papillary muscle moved $7.5 \pm 1.0 \mathrm{~mm}$ septally $(P<.001)$ and 2.8 $\pm 0.7 \mathrm{~mm}$ toward the anterior commissure $(P=.002)$.

The significant septal and apical changes in the mitral valve complex during ejection in the Duran ring group, where the mitral valve dynamic 3-dimensional geometry resembled that observed in the control group during ejection is shown in Fig 5. The posterior anulus moved $2.0 \pm 1.6 \mathrm{~mm}$ septally $(P<.001), 1.0 \pm 1.1 \mathrm{~mm}$ apically $(P<.001)$, and $1.4 \pm 0.7 \mathrm{~mm}$ toward the anterior commissure $(P<.001)$. The anterior anulus moved 1.6 $\pm 1.7 \mathrm{~mm}$ septally $(P<.001)$ and $1.0 \pm 1.1 \mathrm{~mm}$ apically $(P<.001)$. The anterior leaflet moved $0.9 \pm 1.2 \mathrm{~mm}$ apically $(P<.001)$ but did not move toward the septum. The posterior leaflet, as in the other 2 groups, moved $1.8 \pm 1.5 \mathrm{~mm}$ septally $(P<.001)$. Both the anterolateral and the posteromedial papillary muscles moved 3.1 $\pm 1.8 \mathrm{~mm}(P=.018)$ and $4.4 \pm 1.5 \mathrm{~mm}(P=.002)$, respectively, toward the septum.

Aortomitral angle during ejection. The aortomitral angle narrowed slightly in all 3 groups from a maximum value at end IVC (control, $105 \pm 7$ degrees; Physio ring, $105 \pm 7$ degrees; Duran ring, $105 \pm 3$ degrees) to a minimum value at end-systole (control, $103 \pm 7$ degrees; Physio ring, $103 \pm 6$ degrees; Duran ring, $103 \pm 4$ degrees). These changes were small but statistically significant (control, $P=.002$; Physio ring, $P=.011$; Duran ring, $P=.009)$.

\section{Discussion}

Displacement of the AMVL toward the LV septum and into the LVOT during ejection, also known as systolic anterior motion, is the common final pathway of LVOT obstruction. Why this displacement occurs after mitral valve repair with or without ring annuloplasty is not completely understood. Furthermore, whether rigid or flexible annuloplasty rings equally predispose the anterior leaflet toward an obstructive configuration is also unclear, because both the semirigid Physio ring and the flexible Duran ring have been shown to abolish annular area and perimeter changes during the cardiac cycle. ${ }^{13}$ Since the first description of LVOT obstruction after mitral valve repair, ${ }^{1}$ investigators have proposed both valvular and subvalvular mechanisms to explain this phenomenon. Because we observed changes at both the valvular and subvalvular levels in this experiment, we postulate a unified mechanism to explain displacement of the anterior leaflet into the LVOT.

Systolic anterior motion of the leaflets can be explained by valvular mechanisms, which invoke changes in mitral valve geometry, and by subvalvular mechanisms, which focus on perturbations of the papillary muscles. Valvular mechanisms may be primary disturbances of the mitral anulus, disturbances in leaflet coaptation, or changes in LVOT geometry. Advocates of the first mechanism propose that anterior displacement of the posterior LV wall, disparity between leaflet covering area and annular area, and narrowing of the aortomitral angle all contribute to 
position the mitral leaflet abnormally into the LVOT after rigid ring annuloplasty. ${ }^{6,7}$ Other investigators refute those findings and propose that septal displacement of the leaflet coaptation zone displaces the anterior leaflet into the LVOT. ${ }^{8}$ Proponents of LVOT geometric changes base their theory on the observation that the LVOT narrows after the operation in patients in whom systolic anterior motion develops; the narrower LVOT creates faster flow within the LVOT and by the Bernoulli effect drags the anterior leaflet into the LVOT. $^{2-5}$

Subvalvular mechanisms causing systolic anterior motion of the leaflets have been investigated mostly in the context of LVOT obstruction that occurs in patients with HCM. ${ }^{9-12}$ Those theories propose that altered geometry of the papillary muscle-mitral valve complex initiates systolic anterior motion through abnormal distribution of chordal tension on the mitral valve. Septal displacement of the papillary muscles slackens the chordae tendineae of the anterior leaflet and increases the tension on the chordae to the posterior leaflet. Inward displacement of the papillary muscles toward each other slackens the central leaflet and increases the tension on the lateral aspects of the leaflets. This redistribution of chordal tension displaces the leaflets anteriorly and creates central buckling of the anterior leaflet, with the net effect being displacement of the leaflets into the LVOT.

No one has promulgated a theory that integrates the valvular and subvalvular mechanisms of LVOT obstruction after ring annuloplasty. We postulate that systolic anterior motion probably does not occur after ring annuloplasty unless there are changes at both the valvular and subvalvular levels. We propose a mechanism that invokes changes at the annular level that in turn lead to changes in papillary muscle geometry, a mechanism similar to that of LVOT obstruction in patients who have HCM.

In the animals that underwent annuloplasty with the semirigid Physio ring, we observed that the anterior leaflet was displaced toward the LVOT with respect to the control group at the beginning of ejection and that the leaflet moved farther toward the LVOT during ejection. Those changes occurred in conjunction with changes at both the valvular and subvalvular levels. Furthermore, the subvalvular changes in papillary muscle geometry parallel those in the papillary musclemitral valve geometric mechanism of systolic anterior motion found in patients with HCM and LVOT obstruction. On the other hand, we did not observe displacement of the anterior leaflet toward the LVOT at either the beginning of or during ejection in the animals that received a flexible Duran ring. We also did not observe changes at the subvalvular level in that group relative to the control group.

Because the anulus is connected to the papillary muscles through the leaflets and chordae tendineae, we postulate that, in the Physio ring group, the large anterior and posterior annular displacements toward the LVOT at the beginning of ejection and their septal motion during ejection tighten the chordae tendineae and displace the papillary muscles septally. Small displacements of the posterior anulus may be compensated for by apical displacement of the posterior leaflet free edge to slacken the chordae tendineae and allow the papillary muscles to remain in their native position. Larger annular displacements, as observed in the rigid ring group, cannot be adequately compensated for, and the anulus pulls the papillary muscles in the direction of its displacement.

The anterior anulus is normally flexed atrially and away from the LVOT. Similar to what other investigators found, ${ }^{17-20}$ we found that this flexion angle increases during systolic contraction, when the posterior anulus moves toward the LVOT, to maintain the anterior anulus away from the LVOT during ejection. The semirigid Physio ring flattened the anulus and positioned the anterior anulus into the LVOT. Furthermore, during ejection, the rigid coupling between the posterior and anterior annular segments inhibits systolic flexion, and the septal movement of the posterior anulus also moves the anterior anulus septally and farther into the LVOT. This displacement of the anterior anulus into the LVOT may also exert a septal pull on the papillary muscles through commissural and anterior leaflet chordal attachments and thereby contribute further to the displacement of the anterior leaflet into the LVOT.

Although both semirigid and flexible rings abolish dynamic annular area and perimeter change during the cardiac cycle, ${ }^{13}$ we have shown that a flexible mitral annuloplasty ring preserves the conformational geometry of the native anulus better than does a semirigid ring and, therefore, does not appear to perturb the subvalvular apparatus in a direction that predisposes to LVOT obstruction. This hypothetical mechanism of LVOT obstruction suggests that annular remodeling procedures that preserve the ability of the anterior anulus to flex atrially and away from the LVOT, such as with a flexible annuloplasty ring, are less likely to predispose to LVOT obstruction. Moreover, it is possible that conditions that disturb the coupling of the anulus to the papillary muscles (eg, rigid ring annuloplasty or mitral repair with a posterior leaflet "sliding-plasty" to reduce the height of the remaining posterior leaflet scallops) might be more likely to predispose the heart to LVOT obstruction after the operation. 
Limitations. This experiment was performed in normal sheep hearts; differences between human and ovine cardiac anatomy, especially in the posterior anulus, have been described. ${ }^{21}$ Although the rings were sized according to standard clinical criteria, reducing the orifice size of a normal mitral anulus is distinctly different than reducing the size of a dilated mitral anulus caused by longstanding mitral regurgitation, where the bulk of the annular dilatation occurs in the posterior annular region. Furthermore, chronic mitral regurgitation leads to LV dilation and outward displacement of the papillary muscles away from their native positions. Bolling and colleagues ${ }^{22}$ have shown that mitral annuloplasty with a very small ring in patients with a dilated ventricle results in LV remodeling that may induce further perturbations of the papillary muscle configuration. Because we performed this experiment in normal ovine hearts, this study cannot be expected to simulate exactly the effects of ring annuloplasty on the valvular and subvalvular structures in patients. We only observed 3dimensional geometric changes in the mitral valve complex that theoretically predispose to LVOT obstruction in the Physio ring group; it should be emphasized that we did not confirm any hemodynamic degree of LVOT obstruction. LVOT obstruction may have been limited by normal-sized leaflets, anulus, or left ventricle in these ovine hearts. Mitral valve repair procedures in the setting of redundant leaflets and a dilated anulus, as in the typical human condition, may be a prerequisite to create obstruction. Finally, animals in the 2 ring groups were randomized with respect to the type of ring used, but the control (no ring) animals were not randomized.

We thank Mary K. Zasio, BA, Carol W. Mead, BA, and Erin K. Schultz, BS, for technical assistance and Lyn Dupré for editorial assistance.

\section{REFERENCES}

1. Termini BA, Jackson PA, Williams CD. Systolic anterior motion of the mitral valve following annuloplasty. Vasc Surg 1977;11:55-60.

2. Kronzon I, Cohen ML, Winer HE, Colvin SB. Left ventricular outflow obstruction: a complication of mitral valvuloplasty. J Am Coll Cardiol 1984;4:825-8.

3. Galler M, Kronzon I, Slater J, et al. Long-term follow-up after mitral valve reconstruction: incidence of postoperative left ventricular outflow obstruction. Circulation 1986;74(Suppl):I99-103.

4. Kreindel MS, Schiavone WA, Lever HM, Cosgrove D. Systolic anterior motion of the mitral valve after Carpentier ring valvuloplasty for mitral valve prolapse. Am J Cardiol 1986;57:408-12.

5. Schiavone WA, Cosgrove DM, Lever HM, Stewart WJ, Salcedo EE. Long-term follow-up of patients with left ventricular outflow tract obstruction after Carpentier ring mitral valvuloplasty. Circulation 1988;78(Suppl):I60-5.

6. Mihaileanu S, Marino JP, Chauvaud S, et al. Left ventricular outflow obstruction after mitral valve repair (Carpentier's tech- nique): proposed mechanism of disease. Circulation 1988;78 (Suppl):I78-84.

7. Jebara VA, Mihaileanu S, Acar C, et al. Left ventricular outflow tract obstruction after mitral valve repair: results of the sliding leaflet technique. Circulation 1993;88[part 2]:30-4.

8. Lee KS, Stewart WJ, Lever HM, Underwood PL, Cosgrove DM. Mechanism of outflow tract obstruction causing failed mitral valve repair: anterior displacement of leaflet coaptation. Circulation 1993;88[part 2]:24-9.

9. Levine RA, Vlahakes GJ, Lefebvre X, et al. Papillary muscle displacement causes systolic anterior motion of the mitral valve: experimental validation and insights into the mechanism of subaortic obstruction. Circulation 1995;91:1189-95.

10. Levine RA, Vlahades G, Weyman A. Anterior papillary muscle displacement causes systolic anterior motion of the mitral valve in the absence of septal hypertrophy. J Am Coll Cardiol 1988; 11:74A.

11. Lefebvre XP, Levine RA, Yoganathan AP. Systolic anterior motion of the mitral valve in hypertophic cardiomyopathy: an in vitro pulsatile flow study. J Heart Valve Dis 1995;4:422-38.

12. Yoganathan AP, Lemmon JD Jr, Kim YH, Levine RA, Vesier CC. A three dimensional computational investigation of intraventricular fluid dynamics: examination into the initiation of systolic anterior motion of the mitral valve leaflets. ASME J Biomech Eng 1995;117:94-102.

13. Glasson, JR, Green GR, Nistal JF, et al. Mitral annular size and shape change in sheep with annuloplasty rings. J Thorac Cardiovasc Surg 1999;117:302-9.

14. Glasson JR, Komeda M, Daughters GT, et al. Three-dimensional regional dynamics of the normal mitral anulus during left ventricular ejection. J Thorac Cardiovasc Surg 1996;111:574-85.

15. Moon MR, Castro LJ, DeAnda A, et al. Right ventricular dynamics during left ventricular assistance in closed-chest dogs. Ann Thorac Surg 1993;56:54-67.

16. Moon MR, DeAnda A, Daughters GT, Ingels NB, Miller DC. Experimental evaluation of different chordal preservation methods during mitral valve replacement. Ann Thorac Surg 1994;58: 931-44.

17. van Rijk-Zwikker GL, Schipperheyn JJ, Huysmans HA, Bruschke AVG. Influence of mitral valve prosthesis or rigid mitral ring on left ventricular pump function. Circulation 1989;80 (Suppl):I1-7.

18. van Rijk-Zwikker GL, Mast F, Schipperheyn JJ, Huysmans HA, Bruschke AVG. Comparison of rigid and flexible rings for annuloplasty of the porcine mitral valve. Circulation 1990;82(Suppl): IV58-64.

19. Komoda T, Hetzer R, Oellinger J, et al. Mitral annular flexibility. J Card Surg 1997;12:102-9.

20. Komoda T, Hetzer R, Oellinger J, et al. The relationship between the mitral annulus and left ventricular outflow tract. ASAIO J 1997;43:932-6.

21. Walmsley R. Anatomy of human mitral valve in adult cadaver and comparative anatomy of the valve. Br Heart J 1978;40:351-66.

22. Bolling SF, Pagani FD, Deeb GM, Bach DS. Intermediate-term outcome of mitral reconstruction in cardiomyopathy. J Thorac Cardiovasc Surg 1998;115:381-6.

\section{Discussion}

Dr Richard P. Cochran (Seattle, Wash). This model that we see today is very elegant, I think you may offer us the possibility for ultimately understanding some of the very diffi- 
cult aspects of microphysiology, particularly how the components interact and how they interact with the heart itself.

I would like to ask a few technical questions just for clarity and then discuss some of your conclusions.

As I understand it, you saw no mitral regurgitation either before or after the operation in any of your animals?

Dr Dagum. That is correct. We did not see mitral regurgitation at any time.

Dr Cochran. There was no aortic incompetence in any of the animals either?

Dr Dagum. That is correct, too. We did not see aortic incompetence after ring annuloplasty in either group.

Dr Cochran. Even with the pushing of the LVOT, that did not make the valve incompetent at all?

Dr Dagum. Interestingly, in spite of the observed narrowing of the LVOT with the semirigid mitral annuloplasty ring, the aortic valve remained competent. Competency was probably preserved because most of the narrowing occurred subvalvularly with the ring sliding under the aortic anulus.

Dr Cochran. As I understand it, there were no markers on the chordae themselves, so I presume that your statements as far as chordal action are presumed by what you saw on the other markers.

Dr Dagum. That is correct; we did not have leaflet markers at the chordal insertion point. We placed markers on each papillary muscle tip and along the central meridians of the AMVL and central cusp of the PMVL. From those markers, we inferred chordal action from the integrated dynamics of the papillary tips and leaflets.

Dr Cochran. You stated in your article that the anterior leaflet had some buckling. Was that also a presumption not observed or did you actually see that?

Dr Dagum. In the semirigid ring group, we saw the anterior leaflet displace toward the LVOT during ejection. Unfortunately, we could not document anterior leaflet buckling (theorized to create LVOT obstruction in patients with HCM) because our leaflet marker array was not sufficiently dense.

Dr Cochran. One of those difficult aspects in the judgment of mitral valve repair is in the sizing. Did you in any way confirm that your sizing was correct, because you had the perfect opportunity to compare the sizing?

Dr Dagum. All sizing was done according to the usual clinical criteria. We used the intertrigonal distance and the size of the anterior leaflet to size the anulus appropriately. At necropsy we did confirm correct ring size based on the intertrigonal distance.

Dr Cochran. I would like to talk about your conclusions a little bit. It seems that if you wanted to create obstruction, one thing you could do is downsize; in looking at your models, the rings seem to downsize the valve so effectively that you buckle the leaflets. Do you think this is a result of having significant downsizing in a normal valve?

Dr Dagum. Thank you for that observation. As I mentioned, all rings were sized according to customary clinical criteria; therefore we did not downsize the valve. The ring annuloplasty did, however, reduce the annular area by approximately $30 \%$ even in nondilated normal ovine hearts.
Dr Cochran. I think one remarkable thing about this is that with downsizing and the remarkable changes in the mitral valve complex, you really didn't demonstrate clinical LVOT obstruction in any of your models, correct?

Dr Dagum. We did not reliably measure the aortic valve pressure gradient, but we did show significant LVOT narrowing with AMVL displacement into the LVOT in all animals undergoing semirigid ring annuloplasty.

Dr Cochran. I mean I think it speaks to a lot of flexibility in what we do clinically, we have a lot more latitude then we actually realize.

One word of caution about one of your conclusions (the observation that your sliding plasty may be difficult or may make the repair worse): I think if it is used inappropriately it might make the repair worse; but I would not condemn on your data and appropriate sliding plasty or any mitral repair technique, because you are dealing with a normal model. Would you like to comment on that?

Dr Dagum. Thank you for that important clarification. We are not condemning the sliding leaflet annuloplasty. Rather, as you observe, we draw attention to the hidden risks of inappropriate valvuloplasty, such as the sliding leaflet annuloplasty, that may disturb the subvalvular apparatus and exacerbate already compromised valvular-subvalvular mechanics.

Dr Cochran. In our computer model, we have conducted 2 tests with flexible and rigid annuloplasty as well, and we confirmed a lot of your findings. But one aspect that we had a little difference on was the chordal apparatus. Van RijkZwikker demonstrated in video models that the chordal apparatus, actually the strut chordae, become tense and the marginal chordae become slackened or relaxed once the leaflets coapted normally. Because you had no regurgitation, why do you think that is changed in this model? Why do you propose it? Why do you think the chordae will be altered so significantly? The strut chord will stay under tension throughout the entire cardiac cycle.

Dr Dagum. We suspect that the tension transmitted to the AMVL through papillary tip displacement is predominantly through the strut chordae. Those chordae insert closer to the anterior anulus and are tensed by both papillary tip displacement and anterior annular displacement after semirigid ring annuloplasty.

Dr Cochran. In summary, I think this is an excellent model. I think it will continue to help us answer many of the questions that we have. I assume that we will shortly be seeing some ischemic regurgitation models treated in the same way.

Dr Dagum. Our laboratory is actively investigating the mechanism of ischemic mitral regurgitation in an ovine animal model. An integrated model of the valvular-subvalvular dynamics during periods of ischemia may help us understand better the cause of mitral regurgitation that results from myocardial ischemia and to select rational treatment alternatives.

Dr Cochran. Just one final comment. Because you alluded to using a partial annuloplasty repair in this model, I think that, if you are going to do this study completely, you should try partial rigid anterior repairing as well, to see if you can confirm the changes that you are speculating. 